\title{
Green design and its application in product design
}

\author{
Wei CHEN \\ Jiangsu Open University, Nanjing, China \\ chenwei@jstvu.edu.cn
}

Keywords: green design; sustainable development ; green products; product design

\begin{abstract}
On the basis of the discussion of green design, the characteristics of green product are analyzed. Pointed out that the green design is the need of sustainable development of human society, is the necessity of sustainable development. In order to make the social and economic sustainable development, we must carry on the green design for the product. And in a car and a refrigerator, for example, illustrate the application of green design in product design .
\end{abstract}

\section{Introduction}

The primary task of industrial design is to design new products of meeting the needs of users and adapting the market competition. And make new products quickly occupy the market.

At any time, the design can stimulate the evolution and development of human society with strong power. Since industrial design was born, it has always been reflected social and human needs, focused on the urgent affairs of human society and solved the major subject in the field of production and life. Modern design concept is accompanied by the comprehensive development of society, more embodies the nature of human, reflects new forms of life, pays attention to environmental protection .

At present, a large number of foreign products enter the market in our country, and our products also go abroad to enter the international market, so that the market competition is more and more fierce. The function of the product is no longer a main factor of consumers purchase.

The timelinessof requirements, the novelty of design, the beauty of moulding, the environmental protection of use are some main factors which the consumers consider.Among them, environmental protection of use is a very importment factor.The design of green product closedly related to environmental protection has been more and more attention .

\section{The birth of green design}

The modern industrial civilization, from generation to today, has brought great wealth to mankind, but it also brought serious consequences for mankind. With the development of the society, the relationship between human and nature is gradually deteriorating, which is mainly reflected in the environmental pollution.

The first is that pollution is becoming serious.Industrial production is inefficient by use of resources and energy, at the same time various waste water, waste gas, waste residue, noise, electromagnetic pollution etc. are discharged in large numbers, to cause environmental pollution, global warming and the destruction of ecological balance. So that it is serious threat to human health and living space.

The second, the resources are exhausted. Along with the acceleration of industrialization, the demand for natural resources is increasing. As human beings do not a good use of resources and the management of resources is not good, natural resources are obvious shortage; As the water has been polluted, the forest has been destroyed, it results in serious shortage of water resources and at the same time brings a lot of plants and animals to die to threat to biodiversity; ......

Moreover, the population is growing. The growth of population, especially population swelling in developing countries intensifies the contradiction between people and food to bring the hunger, poverty, disease and death, eventually threat the human survival and development. 
In the face of all these environmental problems, human beings finally realize that the human survival and development must be based on the existence of the nature, they are symbiosis, harmonious. Under the influence of the ecological culture, people were thinking about how to protect the environment, how to design thinking, hence the birth of green design was born., as shown in figure 1 .

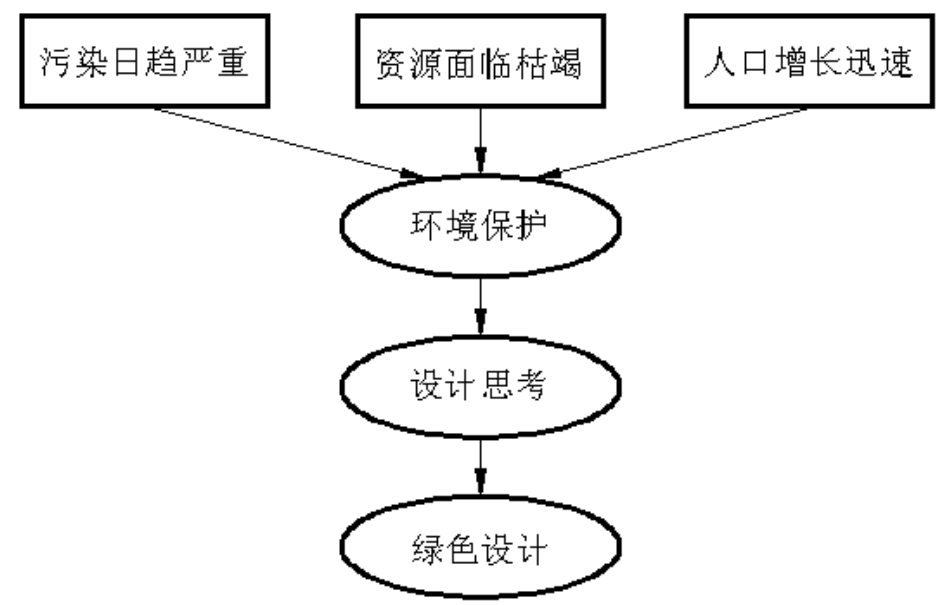

Fig. 1 The birth of green design

\section{The green design}

Green design is a kind of optimization design that under the guidance of ecological philosophy, using the ecological thinking, people bring the design into "human-machine-environment" system, both meeting the needs of the people to pay attention to the protection of the ecological environment and sustainable development and protecting the natural value to promote the common prosperity of man and nature.

Green design can protect human survival environment, and can prevent the waste of resources. Green design is no longer the environment as the constraints of the design process, but as a breakthrough point, it is a kind of new design concept. That green design take the environmental factors as a new value of the product promotion will promot the transformation of production mode and consumption patterns.

\section{Green product and its characteristics}

Using green design method to design the products is called green products. It should have the following features[1]:

1) Good environmental protection

With the development of the society and the continuous improvement of people consciousness of environmental protection, the people pay more and more attention to the environmental protection of the products. Green products have characteristic with saving energy, saving resources, no polluting the environment. It can be easily recycled and reused after useing.

2) Advanced features

Green products adopt advanced technology to easy to use and operate them. The design of various operating device is concise, clear.

3) High efficiency

Green product has higher production efficiency, its conversion efficiency is also higher, self consumption is relatively small.

4) Excellent quality

The quality of product design is an eternal theme. No good product quality will will lose competitiveness. No competitive product also means the waste of resources and energy. Green products have excellent quality. 


\section{5) Low price}

Fierce market competition will inevitably lead to price competition. Selling products at a low price will reduce profit, so we must develop high value-added products, and green product is a typical high value-added products.

6 ) High innovation

The green products of using new technology and new technology can adapt to the fierce market competition, therefore, the product innovation becomes very important. Who is able to continuously introduce new products, who will be able to have the initiative of the product market competition.

7)Short life cycle

With the continuous improvement of people's living level and increase of product variety, life cycle of the green product will be shorter and shorter, which will speed up the development of new products.

8)Many varieties, personalized

Green products meet the people to pursue personalized requirements. People require the function, shape and interior decoration of products to have their own personality, which makes various aspects of the products to have diversity.

9) Small volume

Green product is small in size, not only save resources, but also reduce the space of the product, to carry it very convenient also.

\section{The green design is the necessity of sustainable development}

In order to make the social and economic sustainable development, we must carry on the green design for the product.

People have soberly realized that our priority shoule been sustainable development problems; the sustainable development must be to protect the environment as the important content, so as to realize the natural resources, the carrying capacity of environment in harmony with the development of social economy.

Green design is to make the sustainable development idea into the product design process and to link the ecological environment and economic development into an organic whole with cause and effect each other. In this way, it can make effectively use of resources and energy, and reduce environmental pollution to minimum degree[2].

In a word, the green design is the need of sustainable development of human society, is the necessity of sustainable development.

\section{The application of green design in product design}

Due to the increasingly fierce competition in the market, in order to maintain a strong competitive power and sustainable development, enterprises must adopt green design technology, to develop green products. As a result, the green design has gradually become the behavior specification of the product design.

Taking automobiles and refrigerators as examples illustrate the application of green design in the product design.

1) Green design of car

Car industry is the forerunner of green design. In the past, the design of car was fashionable, luxurious, but now the guiding ideology of design is that a car is environmental, is small and exquisite, can save fuel, can canny out the treatment if tail gas. That is, the green car is developed.

With the increase of car retain quantity, the car tail gases have been the main sources of the urban environment, and is one of the reasons causing the global warming, the greenhouse effect. In order to reduce the emissions of automobile exhaust, the world's major automobile manufacturers are stepped up efforts to develop environmental vehicles. Daimler-benz company has developed a green car, as shown in figure 2 [3]. 
The green car mainly has three major characteristics[4]:

(1) The shape of car front simulates the physiological structureoffish skull.The design structure can greatly weaken the air resistance when the car is running. The structure design of car body simulates fish body shape,its color also does the fish scales

(2) The power system uses a diesel engine with minimal fuel consumption. The average fuel consumption is 4.3 liters per hundred kilometers. At the speed of 90 kilometers per hour, the fuel consumption of per hundred kilometers is only 2.8 litres.

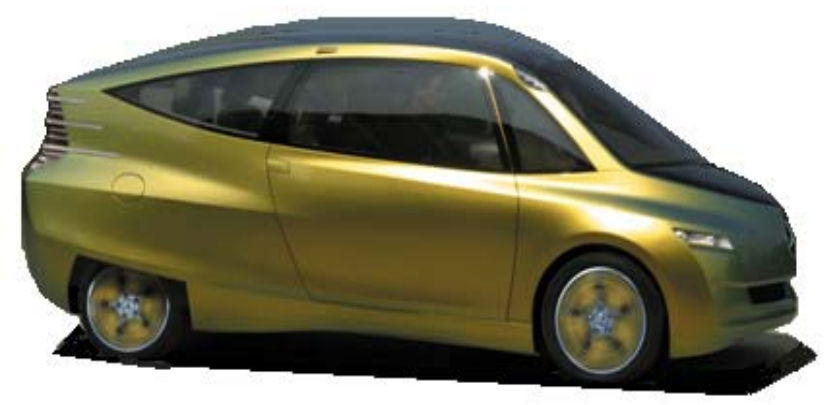

Fig. 2 Environmental protection car

(3) At that time, the car was equipped with a unique selective catalytic reduction degradation device. There is a chemical reagent called AdBlu in the device. When the car produces tail gases, The AdBlu can automatically spray into the automobile exhaust system. Through chemical reaction, the harmful gases are decomposed into water and oxygen and then they are discharged from the tail. After testing, $80 \%$ of harmful gases in the car exhaust are disposed.

In addition, electric cars, solar car, biological fuel car ect. are also the direction of the green car development

2) Green design of refrigerator

Early producing refrigerator used R-12 Freon as a refrigerant. Freon is one of the murderer destroying earth's ozone layer and leading to global warming. So, the first standard of green design of refrigerator must been non-fresno freezers. At present, a refrigerant of refrigerator commonly is R-134a which does not destroy ozone layer and has good safety(no flammable, nontoxic, no explosion,no stimulating, non corrosive).Green refrigerator should also have fresh, antibacterial, energy-saving and mute etc. functions. structure can be removed, and its material may be recycled. That is the real green refrigerator [5], as shown in figure 3.

For disassemble structure, the following principles can be carried out:

(1) Under the premise meeting functional requirements, simple structure and shape are used as far as possible;

(2) The connection is easy to remove and damaged, such as buckle type, multi-piece assembly etc.

(3) Try to avoid secondary processing on the surface of the parts, such as paint, electroplating, coating etc.

(4) Try to avoid embedding metal parts in injection molding parts.

(5) To use the fixed components of the same specifications, and fixed parts should be standardized.

For material recycling, the following principles can be carried out:

(1) the refrigerator design structure should be easy to remove.

(2) To use easily recycled materials, such as thermosetting material, alloy etc.

(3) To use the same material parts as possible components, to use a variety of material parts, such as shake handshandle don't use metal of embedded plastic;

(4)To identify the composition of material.

In the aspects of preservation:

The refrigerator designed from the original single temperature range of zones to upgrade. The foods such as milk, jam etc.which best saving temperature is $2{ }^{\circ} \mathrm{C} \sim 6{ }^{\circ} \mathrm{C}$ generally is put in the freezer. The foods such as fish, meat, some fruits and vegetables are eat in 1 to 2 days is put in zero ice 
preservation, which greenhouse effect is better.Eating meat in two weeks is put in $-7{ }^{\circ} \mathrm{C}$ freezer, no matter what time take out can be cut immediately. The freezer is suitable for storing in the short term would not have eaten the food.

In antibacterial aspects:

The SARS virus brought harm to the human society, so the antibacterial refrigerator got unprecedented attention.Since 1998, haier launched China's first antibacterial refrigerator, antibacterial technology of domestic refrigerator has been constantly breakthroughs. Recently, haier also launched a titanium optical antibacterial technology refrigerator, broke traditional antibacterial refrigerator can only rely on contact technical limitations. At present, this technology has been applied to the haier group 16 categories of series products. Haier is the first enterprises through the national antibacterial certification

That the refrigerator's door used the design of double door sealing struture and more airbag structure can reduce the refrigerator heat transfer by about 3\%; Using optimize the refrigeration system, high efficiency compressor, and improved the coefficient of thermal conductivity of foam layer can make the refrigerator power consumption reduce about $10 \%$.

"Energy saving" is obvious for the benefits of consumers, while the "mute" can relieve the fatigue of people, to make them live in the comfortable environment of family life.

In today's rational consumption, savvy consumers when buying refrigerator not only consider the retail price, also will compare the power consumption of freezer. And mute effect of energy saving refrigerator bring itself is at least conditions of high quality life.
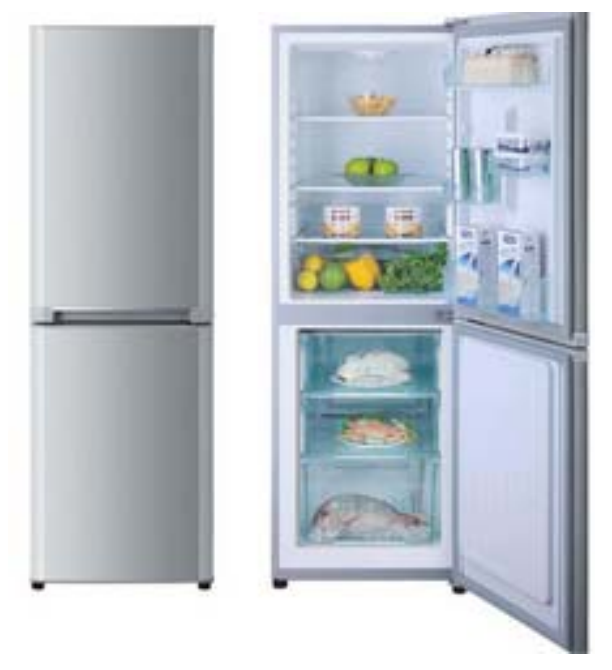

Fig. 3 Green refrigerator

\section{Conclusion}

The research and application of green design has been widely used in product design, and has achieved good economic and social benefits, to improve the competitiveness of products, to reduce the environmental pollution.

To believe that, with the increase of people's awareness of environmental protection, as well as the progress of the green design technology, there will be more green products come out.

\section{Acknowledgments}

This research was supported by project on science and technology innovation team about application of the internet of things technology. 


\section{References}

[1] Zhi-feng Liu: Green design. Mechanical industry publishing house, 1999

[2] Xi-hua Xu: Green desig,-industrial design development inevitably choice, journal of zhejiang university (humanities and social science edition), 1998 (4) : 132-136

[3] Anonymity: Mercedes Benz bionic appreciation.[EB/OL]. http : // www. pcauto. com. Cn / newcar / abroad / benz / other / 0803 /629205.html

[4] The north American international auto show: General new concept car on battery power[EB/OL].. http://auto.enorth.com.cn/system/ 2007/01/09/001512032 SHTML [2004-2-9]

[5] Jia Xiao: Refrigerator health become a bellwether, Choosing Non-fresno freezers to see nameplate. [EB/OL].http://it.sohu.com/43/98/article209959843. SHTML [2003-06-10]

[6] Wen-kai Lan. Introduce to the design and manufacturing on the green refrigerator, Motor and electric technology, 2005 (3) : 58-59 